\title{
The role of shared intentions in the emergence of service ecosystems
}

\begin{abstract}
With the increased prevalence of ecosystems across sectors, understanding what conditions enable their formation is important for both researchers and managers. Servicedominant logic (S-D logic) focuses on service ecosystems, in which actors are interdependent, and characterizes them as layered and nested within three levels (micro, meso, and macro). To understand their formation, this study draws from work in philosophy and the social sciences to introduce the concept of shared intentionality, an aspect of collective agency whose specific conditions result from and foster interdependence among actors, and to acknowledge the mediating role of the meso level in emergence. With these concepts, this study addresses a research question on how service ecosystems are formed and what role individual and collective agency play in this process. This study contributes to S-D logic research by offering a new understanding of service ecosystem formation as a process of emergence in which the development of shared intentions enables collective agency. To synthesize the contribution, this study uses a case to illustrate a conceptual framework in which the sharing of intentions among interdependent actors drives service ecosystem emergence step-by-step across distinct dynamic levels.
\end{abstract}

Keywords: Shared intentions, Service ecosystems, Emergence 


\section{Introduction}

Management researchers are increasingly interested in the development of new collaborative market structures that invite a re-writing of the very premises of how firms think about value creation (Iansiti \& Levien, 2004; Moore, 2013; Williamson \& De Meyer, 2012). Service-dominant logic (S-D logic) lies at the forefront of this rethinking with its concept of service ecosystem, defined as "a relatively self-contained, self-adjusting system of resource-integrating actors connected by shared institutional arrangements and mutual value creation through service exchange" (Vargo \& Lusch, 2016, p. 10). S-D logic highlights the dynamic nature of service ecosystems and stresses the interdependence between actors who integrate resources through service exchange (Vargo \& Akaka, 2012).

Inherent in any analysis of such system dynamics is the agency that individual actors exercise to find solutions and create value for themselves and others in the service ecosystem (Lusch \& Vargo, 2014; Ng, Maull, \& Yip, 2009). Actors' agency allows them “to take actions that shape the ecosystem that others inhabit" (Lusch \& Vargo, 2014, p. 164). Thus, in service ecosystems actors not only exercise their individual agency but also coordinate their actions to improve resource integration and mutual value creation. This coordinated action may result in social structures, which are both the medium and the outcome of social action (Giddens, 1984) and which may enable and/or constrain the agency of individuals (Bhaskar, 2008a). Therefore, a service ecosystem as a social structure exhibits certain institutional arrangements (i.e., rules and resources that directly influence social activities), which, together with agency, are mutually constitutive entities of that system (Giddens, 1984). Furthermore, service ecosystems are layered and nested within three levels: the micro 
(individual), the macro (institutionalized), and the intermediary, or meso, levels (Akaka, Vargo, \& Schau, 2015; Chandler \& Vargo, 2011).

Individual actors (at the micro level) actively strive to collaborate with others to create value, and these collaborations may, under the right conditions, allow service ecosystems to emerge across the meso and macro levels and to remain viable. The term "emergence" is justified in this context: Bhaskar (2008b) defines emergence as the generation (from pre-existing material) of new entities, structures, totalities, and/or concepts that could not have been expected or predicted. In other words, emergence is characterized as a process that results in new properties that are more than the sum of their constituent parts alone. Thus, we can conceptualize service ecosystem formation as an emergent process in which individual and collective agency, together with the institutional arrangements of the social system in which they operate, are mutually constitutive entities of that system.

With the dynamic nature of service ecosystems, scholars as well as managers need to understand the conditions under which individual agency can lead to collective agency and to the emergence of service ecosystems. [Name withheld] (this issue) raises the broader question of how emergent properties may have consequences over and above the individual actors involved in the resource integration process and calls for further research.

To address this gap, we adopt an interdisciplinary approach. Moving beyond marketing/management studies, we take into account contributions from the social sciences and philosophy to introduce "intentionality," a specific aspect of agency that represents individuals' commitment to undertake actions and reach their goals (Bratman, 1987). We focus in particular on shared intentions, which are an aspect of collective agency whose specific conditions result from and foster interdependence among actors (Bratman, 1999, 2014), enabling the service ecosystem emergence. This interdependence develops at the intermediary or meso level (Sawyer, 2005). The study's research question addresses the 
development of shared intentions from the agency of individual actors and the emergence of service ecosystems in the context of actors sharing intentions:

Research question: How do shared intentions develop from individual agency and contribute to the emergence of service ecosystems?

Research conceptualizes service ecosystems in S-D logic as consisting of nested levels (Vargo \& Akaka, 2012). The suggested conceptual framework illustrates their dynamic nature by providing a more detailed understanding of the process by which the macro level emerges from the micro and meso levels (i.e., upward movement and causation) and, in turn, how the macro level provides feedback to and influences the micro and meso levels (i.e., downward movement and causation). By breaking down the levels of emergence (Sawyer, 2005) and introducing the dynamics between individual and shared intentionality (Bratman, 2014), the framework details the role of shared intentions in the emergence of service ecosystems. We contribute to the further development of S-D logic by introducing work that reconciles agency-structure frameworks that seem incompatible, particularly Bratman's $(1999,2014)$ work on shared intentionality and Sawyer's (2005) work on the mediating role of the meso level in emergence.

The structure of this article is as follows: Section 2 introduces the conceptual building blocks of the framework. We begin by discussing how S-D logic accounts for service ecosystem dynamics, then develop the concepts of agency and shared intentionality, and, finally, present the social emergence paradigm. Section 3 present the conceptual framework, which compiles the concepts introduced in Section 2. Section 4 illustrates the development of shared intentions and their effects on the emergence of a new service ecosystem in Latin America. Finally, the article provides theoretical contributions and proposes future research directions and implications for managers.

\section{Toward a conceptual framework}




\subsection{Dynamics of service ecosystems}

Firms, customers, suppliers, and other stakeholders constitute service systems that perform value-creating activities by taking on the role of providers, beneficiaries, or partners in the market, to reach desired outcomes (Mele \& Polese, 2011). A recent shift in scholarly attention is from single service systems to service ecosystems (Lusch \& Spohrer, 2012; Maglio \& Spohrer, 2013). This shift reflects the increasing impact of ecosystems across industry sectors, particularly technology (Moore, 2013; Thomas, 2013). Understanding ecosystems' dynamics is an ongoing endeavor not only for S-D logic scholars (Lusch \& Vargo, 2014; Vargo \& Lusch, 2011) but also for management scholars studying ecosystems (e.g., Moore, 1993, 2013; Thomas, 2013). For example, Moore (2013), on examining technologically networked environments, shows that participants with "shared purpose" take on more active and deliberate roles in developing ecosystems. Thomas (2013) uncovers different phases of emergence (i.e., initiation, momentum, and control). Although both Moore and Thomas recognize some level of agency in the emergence of ecosystems, they examine agency as a strategic rather than an individual or social feature. Conversely, S-D logic views ecosystems as deeply social and as formed and re-formed through actor-to-actor interactions in which actors create value by integrating and exchanging resources.

In its conceptualization of the dynamics of service ecosystems, S-D logic adopts a strong structuration perspective (Giddens, 1984; Stones, 2005): actors create structures through their actions, while structures also enable and constrain the actions of actors (Lusch \& Vargo, 2014). This perplexing "paradox of embedded agency" is not unique to S-D logic and is a recurring theme in sociology literature (Battilana \& D'Aunno, 2009; Sawyer, 2005; Sewell, 1992).

The research question focuses on bringing clarity to how actors (in exercising their individual agency and interacting in service exchanges) develop collective agency and thus 
contribute to the emergence of a service ecosystem. S-D logic scholars increasingly recognize actors' agency as one of the features or conditions for the existence of service ecosystems (Vargo \& Lusch, 2016). Each actor possesses an original combination of resources and contributes to the service ecosystem in a unique way. This uniqueness arises not only from individual actors' core competences and distinctive resources but also from their ability to create value by matching resources, inserting themselves into the wider service ecosystem, and contributing to its success and evolution by offering individual solutions (Gummesson \& Mele, 2010).

Related to the agency-structure relationship and of particular interest to the current work is the S-D logic characterization of the service ecosystem structure as layered and nested within three levels: micro, meso, and macro (Akaka et al., 2015; Chandler \& Vargo, 2011). Causal relationships between actors at one level may generate events at another level (Lusch \& Vargo, 2014). Processes moving from the micro level to the macro level (and vice versa) occur "in a sea of change, making all the systems inherently dynamic" (Lusch \& Vargo, 2014, p. 170) over time and space. The term "system (re-)formation" (Vargo \& Akaka, 2012) captures the recursive processes by which these systems form and re-form both dynamically and continuously.

In exploring the role of agency (both individual and collective) in the process of the emergence of service ecosystems, we adopt the term "emergence" instead of "(re-)formation" (Vargo \& Akaka, 2012). The concept of emergence appears widely in the literature, not just in systems science (e.g., Gell-Mann, 1994; Kauffman, 1995) and management (Thomas, 2013; Van de Ven \& Garud, 1993) but also in the philosophy of science (e.g., Bhaskar, 2008a; Mandelbaum, 1951; Meehl \& Sellars, 1956), sociology (e.g., Archer, 1982; Buckley, 1967), psychology (e.g., Davidson, 1999), and linguistics (e.g., Chomsky, 2002). As such, use of the term reflects this study's multidisciplinary approach. More important, we highlight 
the role of human agency in emergence and provide a central distinction: while the literature on service ecosystems apprehends the micro, meso, and macro levels as static, the current emergence conceptualization adopts a more dynamic analysis of these different levels.

Through the service ecosystem lens, value creation appears in all its complexity and comprises both every individual actor's contribution and the collective role actors perform as they exchange resources in their interactions. However, in accordance with the research question, what remains to be understood is how service ecosystems emerge from human agency and the processes that characterize this emergence. We suggest that the answer to this question begins with shared intentionality, an aspect of collective agency.

\subsection{Agency and shared intentionality}

As discussed, S-D logic recognizes that as individual actors engage in value-creating interactions, their agency plays a crucial role in shaping service ecosystems. Here, we explore how the concepts of individual and shared intentionality are linked to agency and, thus, to the emergence of service ecosystems.

Individual agency refers to the exercise or manifestation of the capacity to act (Stanford Encyclopaedia of Philosophy, 2015), while collective agency occurs when two or more individuals act as a group (Stanford Encyclopaedia of Philosophy, 2015). As stated in Section 1, intentionality constitutes a specific aspect of agency (Searle, 1983): intentions are the states of mind that individuals adopt as they commit to undertake actions and reach their goals (Bratman, 1987). During the past three decades, the development of collective agency, and its relationship to both individual and shared intentionality, has preoccupied psychologists (Tomasello, 2009), sociologists (Archer, 2000, Sawyer, 2005), and philosophers (Bratman, 1999, 2014; Gilbert, 1990; Searle, 1983). Consumer behavior research on intentional social action ("group action") largely draws from the last group (e.g., Bagozzi, 2000; Bagozzi \& Dholakia, 2002). Bagozzi (2000) notes that while these scholars 
may diverge on philosophical nuances, they represent a fairly unified picture of shared intentionality.

We draw on Bratman's $(1999,2014)$ work on shared intentional activities for several reasons. First, that research is informed in part by the behavior of complex collaborative systems (analogous to service ecosystems). Second, Bratman recognizes that shared intentional activity requires both individual intention and adherence to certain social norms present in institutional arrangements. Third, Bratman explores the nature of intentionality and agency in depth and identifies the conditions necessary for the adoption of shared intentions. Finally, this choice aligns with Bagozzi's (2000, p. 391) argument that Bratman's approach to shared intentions allows for "the study of groups doing things intentionally, achieving group goals, and experiencing group outcomes."

Bratman (1987) indicates that intentions are arranged hierarchically: higher-order intentions demand the adoption and fulfillment of lower-order intentions. For example, an academic's intention to publish a paper demands adopting and fulfilling the intentions of writing and sending the paper to the appropriate journal. Furthermore, both the internally held norms and values of the individual, as well as the external norms imposed by society, constrain the commitment element of intentions (Archer, 2000; Bratman, 1987). The influence of these norms is associated with the role of intentions in coordinating actions: pursuing everyday complex goals requires some level of commitment to develop the intrapersonal and interpersonal coordination necessary for actors to prioritize among their own actions and to synchronize them with those of others. In this way, individual intentions facilitate and are constrained by sociality.

Some individual intentions, pertaining to shared activities involving an element of interdependence, incorporate a higher degree of sociality. When actors' intended actions are interdependent, they develop shared intentions — that is, individual intentions that several 
actors have in common — to participate in a shared activity (Bagozzi, 2000; Bratman, 1999, 2014). In other words, shared intentionality supports or motivates collective agency. Importantly, such intentionality does not mean that actors' overarching intention to participate in the activity or their individual goals are the same. For example, consider faculty members in a department who collectively intend to teach a set of courses, but do not necessarily intend to do so together. Conversely, when teaching the same program, professors, as a coordinated and interdependent entity, largely share their intention to deliver certain learning outcomes to their students and consider who else is going to contribute to the particular portions of the learning objectives. While they may not have the same individual goals (some teach for the love of teaching, others for money), they share the intention to deliver a program together, integrating their knowledge and skills.

Bratman $(1999,2014)$ exemplifies shared intentional activities as singing a duet together. A duet requires that individuals hold intentions that are different from simply "I intend to sing" or even "I intend to sing at the same time or in the same room as my friend." In other words, their shared intentions are more than simply adding up their individual intentions to sing (Shapiro, 2002). "Deep continuity" (Bratman, 2014, p. 4) exists between individual and shared intentions. Bratman's characterization of this continuity asserts that the conditions that need to be added to individual intentions to ensure shared intentionality do not alter the basic nature of individual intentions: shared intentions are based on "augmented individualism" (Bratman, 2014, p. 2).

From the S-D logic perspective, the concept of continuity from individual to shared intentionality sheds some light on the dynamics of actor interactions. Continuity not only articulates how intentions are nested within the micro/meso/macro levels of a service ecosystem but also provides an account of the overall process of the emergence of service ecosystems. What is required, then, is some recognition of the conditions and mechanisms 
involved in the emergence of shared intentions from individual intentions, including interdependence. Bratman (2014) describes such conditions through five building blocks:

1. Participants (as intentional actors) hold "interlocking intentions," according to which each participant intends that we (the participants together) perform the joint activity. These intentions are further characterized by drawing on special conditions of:

2. Compatible sub-plans (or "meshing"),

3. Mutual responsiveness (to help each other),

4. Interdependence (each continues to intend that we perform the activity if and only if the others continue to intend to perform the activity), and

5. Shared knowledge of the conditions.

Bratman's continuity view of intentionality means that individual intentions are the basis of shared intentions and also that shared intentions constrain individual intentions. Furthermore, the continuity argument enables us to find the link between the micro level, in which single actors hold individual intentions, and the meso and macro levels in which actors share intentionality.

The "interlocking" of the participants" intentions ("I intend that we engage in the activity") is associated with an activity that could not be undertaken individually and in which participants are interdependent. Shared intentions clearly rely on interactions among actors for them to develop shared knowledge of each other's intentions to proceed, for these intentions to mesh, and for the actors to help each other achieve their goal. Next, we turn to the role of interactions in the emergence of structures, such as service ecosystems.

\subsection{The social emergence paradigm}

Understanding emergence is about uncovering the features of individual agency that serve as the basis for collective behavior. Bratman's $(1999,2014)$ work on the building of 
shared intentions provides a link between individual agency and collective agency. Shared intentionality is a form of structuring or institutional arrangement (Vargo \& Lusch, 2016) with recursive properties: shared intentions constrain and guide individual intentions. While they highlight the construction of a structured arrangement, the building blocks of shared intentionality do not sufficiently account for the role of the interactions that support them. Marketers as far back as Alderson (1957) view markets as "organized behavioral systems of exchange" (Bagozzi, 1974, p. 77) made possible by interactions between market actors. S-D logic upholds this perspective in recognizing the crucial role of interactions: "actor-to-actor exchanges and interactions ripple through tiers of actors, resulting in the emergence of what is a relatively self-contained structure" (Lusch \& Vargo, 2014, p. 163). However, the emergence literature disagrees about the role of interactions in emergence. The notion of emergence (Sawyer, 2005) accounts for intermediary levels of analysis between the micro and macro levels, in the form of social and cultural features resulting from the interactions of individuals and groups. Sawyer (2005) provides a thorough review of the broad literature on emergence in the $19^{\text {th }}$ century; of particular relevance to the current study is his analysis of the role of interactions in emergence by contrasting two types of accounts: the structure paradigm and the interaction paradigm.

While structurationists, such as Giddens (1984), and interactionists, such as Bourdieu (1977), account for the mediational processes between the individual and the collective levels, Sawyer (2005) finds fault in both accounts. Sawyer (2005, p. 209) recognizes Giddens's attempt at establishing an intermediary level derived from social interactions with some degree of causality over the two other (individual and institutional) levels but finds that this attempt falls short of convincingly bridging the gap between the two levels by failing to provide a "theory of interaction." Instead, he agrees with Sewell (1992) that the virtual nature 
of the "rules" that constitute Giddens's intermediary level disconnects them from real phenomena, such as language or other interaction practices.

On the interactionist side, Bourdieu's (1977) habitus recognizes interactions at an ontologically autonomous level that connects individuals with structures and without which structure cannot be explained (Sawyer, 2005). However, without a higher-order autonomous structure level, interactionism accounts for neither the structural constraints on individuals nor the autonomous agency of individuals: "Bourdieu's habitus retains precisely the agentproof quality that the concept of the duality of structure is supposed to overcome" (Sewell, 1992, p. 15). In other words, required is an alternative account of emergence that combines autonomous individual and institutional levels to fully account for the roles of agency and structure, as well as an autonomously ontological interaction level that not only recognizes the crucial role of interactions but also sets the stage for exploring how interactions contribute to the emergence of social structure. Sawyer's (2005) social emergence paradigm addresses this need by establishing five ontological levels ranging from the individual to the wider institutional social structure (see Fig. 1). These ontological levels show the role of social practices, such as communication, in fostering emergence (first ephemeral, then stable), in creating structure, and, conversely, in mediating the constraining effects of structure on interactions and individuals. 
Fig. 1. The social emergence paradigm (adapted from Sawyer, 2005).

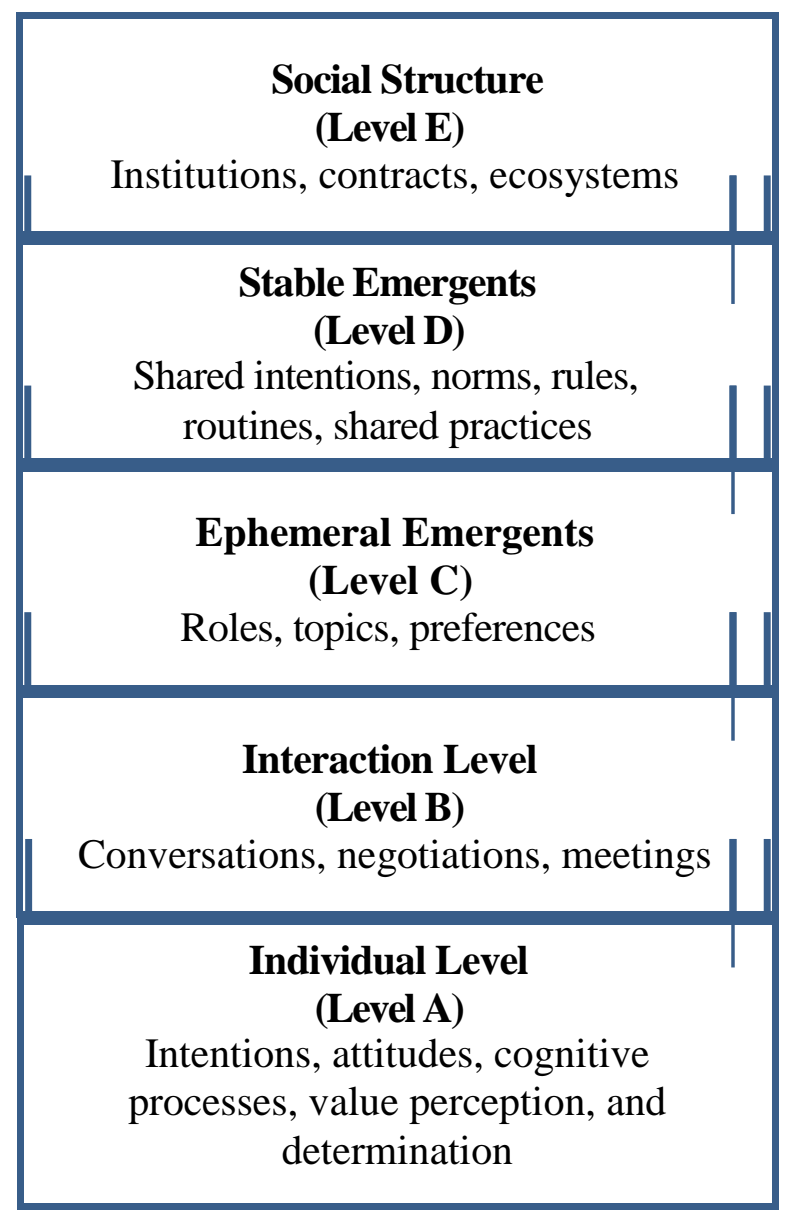

Individual level (level A): This level includes individual properties such as intention, agency, memory, personality, and cognitive processes and is associated with value and meaning. This level is where individual preference judgments are made and where the individual interpretation of "dynamic and somewhat malleable discourses and practices" (Peñaloza \& Mish, 2011, p. 22) is formed.

Interactions level (level B): This level encompasses interactions across different types, such as discourse, collaboration, and negotiation among individuals. Important for the current work is the level of service exchange in which actors integrate and exchange resources to create value. 
Ephemeral emergent level (level C): This level includes properties such as topic, context, interactional frame, participation structure, relative role, and stature assignments. This level begins to structure the social entity and, more important, to constrain the subsequent two levels. For example, after a topic of discussion has been established or the roles of individuals in a group recognized, any change to these emerging properties requires real justification.

Stable emergent level (level D): This level includes social properties, such as group subcultures, group slang, and catchphrases; conversational routines; shared social practices; and collective agency (including shared intentionality). At this level, norms and standards flow from, but also inform, more institutionalized structures (Archer, 2000; Peñaloza \& Mish, 2011).

Social structure level (level E): This level includes written texts, such as contracts, procedures, laws, and regulations, in which material systems and infrastructures emerge in the formalized artefacts of a social structure. In this level, institutional arrangements find their ultimate form. This level contains larger social patterns and trends (Peñaloza \& Mish, 2011).

For Sawyer (2005), structure itself emerges from the formalization of these emergent features, to form institutions. Implicit in this emergence paradigm is the notion that the emergent whole is more than the sum of its constituent parts. That is, the interaction of these constituent parts enables the emergence of a new whole. Not only do specific new properties emerge, but so, too, do organizing structures or institutional arrangements. These emergent processes account for bottom-up effects. At the same time, institutions exert downward forces; structure does indeed constrain the emerging agency of the collective and the individual. As stated previously, shared intentionality is a form of structuring or institutional arrangement with recursive properties; shared intentions constrain and guide individual 
intentions. These structures are important in that the relationships they represent have causal powers and because different properties and powers emerge at each level of social reality.

\section{A conceptual framework for the role of shared intentions in the emergence of service} ecosystems

This study's conceptual framework provides a fuller understanding of how individual and collective agency spur the emergence of a service ecosystem. To enrich the understanding of service ecosystem dynamics in S-D logic, we bring two complementary theoretical works together. First, Bratman's (2014) conditions for shared intentionality address the gap in understanding of how agency contributes to the emergence process by showing how the individual intentions of interdependent actors turn into but are also constrained by shared intentions. Second, Sawyer's (2005) social emergence paradigm recognizes five levels within the process of social emergence. This section reveals how the conditions of shared intentions manifest themselves in each level and thus play a role in the emergence of the service ecosystem.

Bratman's (2014) and Sawyer's (2005) accounts are related, as the building of shared intentionality is part and parcel of the emergence process: shared intentions belong to the emergent properties that result from the interactions of interdependent actors. Crucially, we argue that the emergence of shared intentionality is pivotal to the value co-creation processes that result in service ecosystem emergence. S-D logic scholars argue that social norms and practices act "as a central driver of the actions and interactions that enable value creation and service system (re)formation" (Vargo \& Akaka, 2012, p. 208). Shared intentionality does the same, as we noted in the discussion on the continuity of individual and shared intentions: shared intentions may constrain the individual intentions that underlie them. As actors transition from individual to shared intentions and exercise collective agency, they contribute to the formation of institutional arrangements. More important, the five conditions of shared 
intentionality play an important role in the structuration process, and thus we argue that shared intentionality has a powerful effect on the emergence of the service ecosystem as a whole. This interdependence of actors contributes to the sharing of intentions and produces a momentum that drives the emergence from individual agency to collective agency. In short, shared intentions, due to their distinctive properties, contribute to the emergence of a specific instance of collective agency: service ecosystems.

We present the framework in Fig. 2, which integrates Sawyer's (2005) five levels of social emergence, Bratman's (2014) emergence of shared intentionality, and the S-D logic account of service ecosystem development through resource integration and service exchange processes. Together, levels A and B correspond to the micro level in S-D logic, defined as the level that frames exchange among individual actors (Akaka et al., 2015; Chandler \& Vargo, 2011). Level A operates at the micro level of individual actors, who can fulfill their higherorder intentions by adopting lower-order intentions requiring resource integration and service exchange. They assess their own resources and consider opportunities to access others' resources and contribute their own. Fig. 2 shows that individuals, at this level, are potential resource integrators but that links are not yet formed. At level B, actors form the interactions necessary to enable their interdependence (Akaka et al., 2015; Vargo \& Akaka, 2012) and their ability to match resources and insert themselves into the wider service ecosystem (Gummesson \& Mele, 2010). From an intentionality perspective, interactions with other actors communicate intentions (e.g., to interlock, to mesh, to be mutually responsive). 
Fig. 2. The service ecosystem emergence framework (adapted from Akaka et al., 2015; Bratman, 2014; Lusch \& Vargo, 2014; Sawyer, 2005).

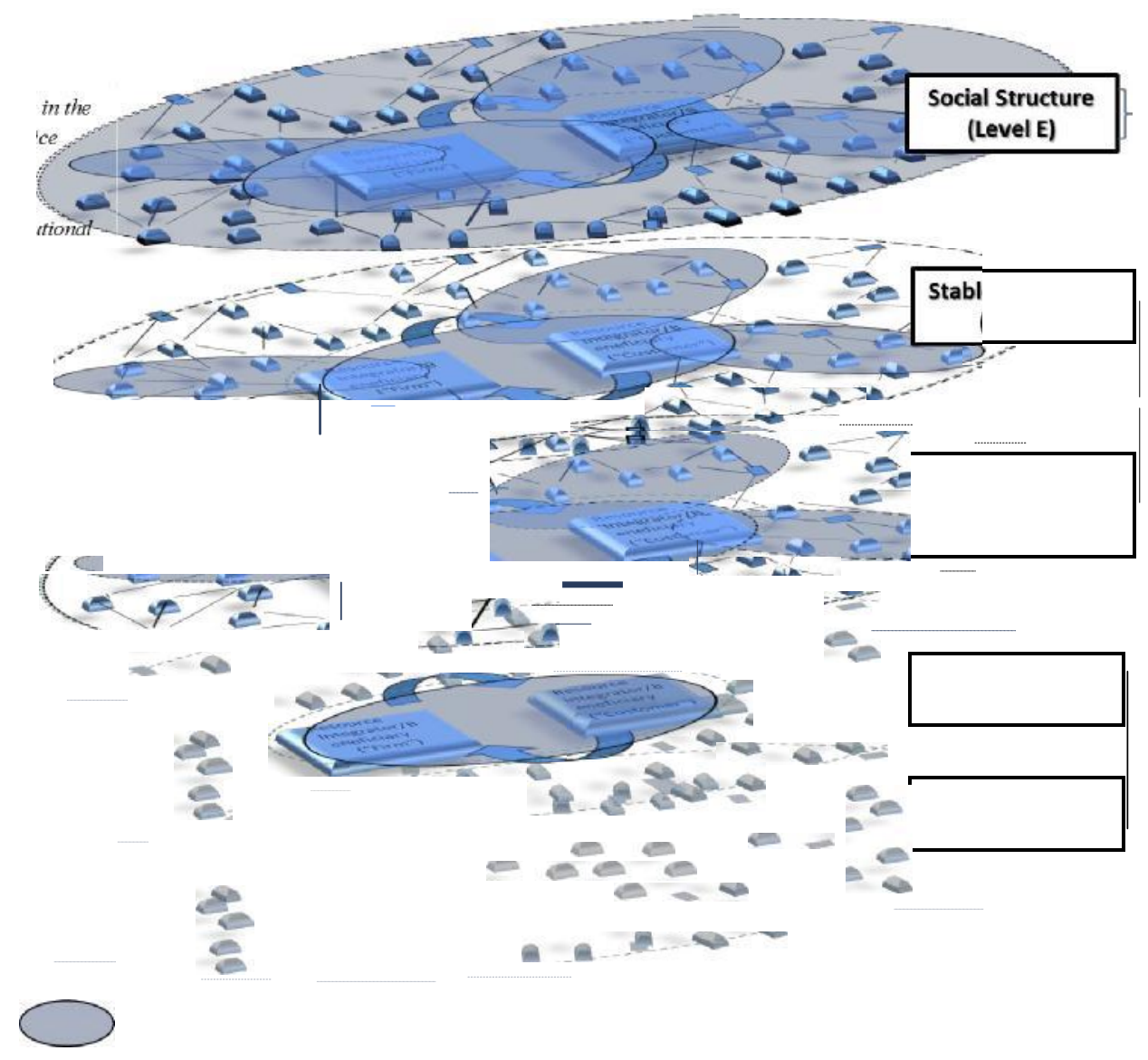

Levels $\mathrm{C}$ and $\mathrm{D}$ constitute the meso level of a service ecosystem in which mid-range structures and activities typical of firm and customer networks and institutions occur (Akaka et al., 2015; Vargo \& Lusch, 2016). As more exchanges take place among actors, patterns emerge in interactions and give rise to "ephemeral emergents" (level C). These ephemeral emergents are features of interactions, such as the topic of the exchanges, preferences, and role assignments. From an intentionality perspective, at this level emerging norms and values are linked to commitment. Actors begin to focus on one another's intentions and the we that is implicit in service exchange. Symbolic communication and socially constructed meaning enter into play here, as they do more generally in value creation (Spohrer \& Maglio, 2010). 
With continued exchanges, emergent features stabilize (level D). Relationships become more stable and are marked by resource-integrating and service exchange practices that create value and institutional arrangements, such as rules and norms (Akaka et al., 2015; Bratman, 2014; Sawyer, 2005). At this point, routine practices are sufficiently entrenched for shared intentionality to take hold: individual intentions are clear and can interlock, sub-plans can be meshed, individuals can rely on others' commitment and support in creating value, and institutions are formed and supported.

Finally, formalization of these relationships occurs at level E: shared intentionality, while still present, is reified and externalized in the form of contracts and conventions characterized by the formation of institutional arrangements. The macro level is the domain of "broader societal structures and activities" (Vargo \& Lusch 2016, p. 17). This level is more formal, and thus less subject to fluctuation, and encompasses durable institutions and rules for "how the actors at micro and macro levels assemble into communities" (Lusch \& Vargo, 2014, p. 170).

We consider two important points in relation to this process description. First, what seems like a temporal description for expository purposes is foremost a causal emergence of complex sociality, in which the role of temporality is primarily associated with repetition and diffusion. Second, while this description is uni-directional (bottom up), each level enables and constrains the ones that follow, so influence is bi-directional. The arrow on the left-hand side of Fig. 2 shows this bi-directionality.

\section{An illustration}

We illustrate the conceptual framework through a specific case: the development of a new business organization in Latin America, Sistema B, and the service ecosystem that emerged around Sistema B. Case studies can be adopted as motivation, as inspiration, or as illustrations of conceptual contributions (MacInnis, 2011; Siggelkow, 2007), in which the 
role of illustrations is to assist readers by helping them imagine "how the conceptual argument might actually be applied to one or more empirical settings" (Siggelkow, 2007, p. 22). In these situations, the case is selected for its ability to exemplify and is presented after the conceptual discussion. We chose the Sistema B service ecosystem case for its clear, recent, and extensive example of the core concepts we present. We developed the illustrative case through interviews with two key individuals involved in the process of establishing Sistema B Argentina (Virginia Pittaro, executive director of Sistema B Argentina, and Pedro Tarak, co-founder of Sistema B Argentina and co-founder of Sistema B International), as well as through the first-hand involvement of one of the authors in the unfolding emergence of the Sistema B service ecosystem.

In the interviews with Virginia and Pedro, the development of their shared intentions was compellingly traceable throughout the formation of Sistema B and its service ecosystem. A verbatim analysis — text mining and lexical analysis —allowed us to extract significant issues (Richardson \& Adams St. Pierre, 2000) or primary categories (Gummesson, 2005). The aim of this analysis was to identify illustrations of the role of agency and shared intentions in the data.

Sistema B is a non-profit organization, founded in 2011, whose goal is to build a beneficial environment for B-corporations, or companies that use the power of business to solve social and environmental problems. To date, 132 certified B-corporations are located in Latin America. The case illustrates the emergence of shared intentions and their role in the emergence of the Sistema B service ecosystem. We organize the discussion of the upward and downward causation mechanisms in "pairs" of adjacent levels.

\subsection{Effects of individuals on interactions $(A \rightarrow B)$ and effects of interactions on individuals} $(B \rightarrow A)$ 
We depict the upward and downward effects between individuals and interactions to show how these two lowest levels of emergence act to prime the emergence engine. Cofounder Pedro is clear on the origin of Sistema B. He and his co-founders had been individually reflecting on the next steps in their professional lives and decided to engage in what he calls "quality conversations." His use of the term is indicative of the importance he attributes to the role of these conversations in the emergence of Sistema B. From an S-D logic perspective, these conversations are an example of resource integration between actors. At this point, no norms or practices are established for Sistema B per se (i.e., Sistema B does not yet exist); the actors apply generic norms common to Latin American business executives meeting casually to discuss future business opportunities. The term "quality" refers to an expectation that the conversations will be open and honest and may involve a deeper level of personal involvement than most. Resources include knowledge, expertise, time, intention to engage, honesty, social and communication skills, and more. Numerous conversations took place among the four founders, each of whom had intended to explore new ways of doing business and believed that the first step was speaking with one another to convey their personal beliefs and aspirations for a different way of doing business, in which profitability and wider social benefits might co-exist. In other words, each had a deep sense that these conversations were necessary to develop a common ground of new ideas and a shared approach.

Conversely, conversations also shape the actors' resources: beliefs and intentions are adjusted, knowledge and expertise are increased, and trust is created. Through their conversations, the founders of Sistema B formed new individual intentions to pursue joint efforts to facilitate the establishment of a new business type, one that would allow for alternative approaches to profitability. These intentions may have existed before the conversations but had not been fully articulated or seemed difficult to put into action. In the 
co-founders discussions, constraints were lifted and a way forward was defined. The generic conversational norms at play in the first few conversations influenced the conversations and evolved as these specific actors enacted them in this context.

Bratman (2014) and Sawyer (2005) both highlight the role of communication in emergence processes. Sawyer singles out the ontological status of interactions as a level of analysis and demonstrates the importance of interactions in causing upward and downward effects. Similarly, Bratman discusses the role of communication in enabling the emergence of "modest" sociality due to the formation of shared intentions. Without communication, actors have no way to participate in the shared intentions. As they begin to interact, actors recognize new opportunities, while confronting new constraints. Thus, though they shape the interactions in which they participate, these interactions, in turn, influence their own intentions, as evidence of others' attitudes comes to light.

\subsection{Effects of interactions on ephemeral emergents $(B \rightarrow C)$ and effects of ephemeral} emergents on interactions $(C \rightarrow B)$

Interactions act as enablers of ephemeral emergents, and, in turn, ephemeral emergents exert pressure on interactions. The conversations between the four founders took on, in their words, a "unity in conversation" around recurring topics, such as the integration of social and business goals and the need for an integrated economy. Though still ephemeral, this convergence of topic, frame, and pursuit of clarity enabled further emergence by centering the founders on their potential joint project and constraining their conversations. Although practices had not fully taken hold, the frame of the conversations was now creating a context for the actors to integrate resources within their small group. Conversely, Virginia highlighted how a common language (level C) can increase the number of interactions (level B): "There was a huge increase of interactions, particularly because there is a common (as shared) language, a shared set of values, shared purpose. " At play here are the 
representational practices that foster collaboration (Kjellberg \& Helgesson, 2006; Lusch \& Vargo, 2014). The development of topic and other language regularities, an example of early representational practices, triggers the gradual emergence of shared intentionality by enabling the building of shared knowledge, which we highlight as a building block of shared intentions. Shared knowledge is necessary to generate shared intentions and new social practices. In addition, as certain elements of the conversation develop and are shared (B - C upward causation), doubts, misunderstandings, and other obstacles disappear, and a broader range of participants engage in conversations (C - B downward causation). Thus, interactions spark the development of shared knowledge and other ephemeral emergent properties and enable more interactions to take place, while also allowing individuals to align their thinking and aspirations. These processes also foreshadow a future strategy that will evolve from shared knowledge and understandings.

\subsection{Effects of ephemeral emergents on stable emergents $(C-D)$ and effects of stable} emergents on ephemeral emergents $(D-C)$

Having built common ground, the founders worked to establish a Sistema B service ecosystem. Further conversations and emergent norms and practices helped establish the interdependence of intentions. The interviews highlighted several examples of the C - D impact. Pedro indicated how shared intentions stabilized among the founders when they explicitly asked themselves "Do we want to be part of the transition from a fragmented economy to an integrated economy?" They agreed and, more specifically, aimed to pursue "a new type of company through private agreement, by doing it. "The explicitness and interlocking nature of their private agreement marks the stabilization of their emergent shared intentions.

The interlocking and interdependence of the intentions of the founders and, in time, their associates were critical to the eventual emergence of the Sistema B service ecosystem 
itself. In addition, a discussion around the objective of a long-term economy and the resulting decision to "go down to microeconomics" shows a strategic effort to separate the long-term objectives into tractable chunks, or to "mesh sub-plans." Further developments and decisions solidify the stable intentions and begin to broaden the circle of active protagonists. Virginia illustrated such a development as follows: "one of the key aspects of Sistema B Argentina was not so much what we did but how we did it: we worked with others. We were conscious that given the scope of what we were suggesting we had to build it with others, we knew we didn't have the capacity and that we could not (but also did not want to) do it alone."

The case also illustrates the downward effect of shared intentions. Developing stable shared intentions helped the founders and their followers solidify their own attitudes and behaviors. Beyond the core group, others were affected as well: the emerging Sistema B service ecosystem opened up new opportunities for graduating students by giving them a frame of reference to think about jobs beyond the for-profit/non-profit dichotomy; thus, the alternative route advocated by Sistema B becomes viable. The process of structuration is also visible here. As shared intentions and the norms that govern them emerge, routine practices and norms are accessible to a greater number of actors and across more contexts. The increased interdependence of the actors' intentions leads to an explicit agreement to continue to work together and to reach out beyond the core group. In summary, the full scope of Bratman's (2014) five building blocks for shared intentions is apparent here-from the participants "interlocking intentions" to pursue "a new type of company ... by doing it"; to the meshing of sub-plans evidenced in the comment "It was not so much what we did, but how we did it, we worked with others"; to a mutual responsiveness and interdependence ("we did not have the capacity ... we could not do it alone"); to the shared knowledge of the conditions ("We were conscious that ..."). 


\subsection{Effects of stable emergents on structure $(D \rightarrow E)$ and effects of structure on stable emergents $(E \rightarrow D)$}

In this section, we illustrate the formalization process of the Sistema B service ecosystem in terms of the number of actors, activities, processes, and impact and its ambitions, successes, and needs. For example, Pedro noted a distinction between "a Bcorporation as a concept and as an expression of a new business structure, identity and legal class; and of Sistema B as an organization and a movement at the same time." This statement reflects recognition of the institutions that guide and legitimize the emerging symbols, artefacts, procedures, and systems.

Commenting on the involvement of the different actors, Pedro stated: "They are connected between themselves, but they also have a collective voice in the wider community. It is a much more integrated approach that can be measured by the well-being of individuals, communities, and the planet and not just according to financial standards." Examples of this integrated approach include strategic initiatives, such as the launch of a global, searchable platform to identify local competences and expertise; work with the Argentine government to crowdsource policy proposals; and the development of an impact assessment tool common to each of the Sistema B local communities. Norms, rules, and practices have become formalized in these tools to transcend national and cultural boundaries and solidify the community by influencing the processes and actions of all actors and systems in the Sistema B service ecosystem.

These developments illustrate both bottom-up and top-down processes: social structures, such as interactive platforms and common tools, are instrumental in helping Sistema B enhance participation, which in turn has helped form shared intentions. These structures can both constrain the shared intentions of some actors, by challenging specific 
sub-plans, and support these intentions by increasing participation and the likelihood of success.

\section{Discussion}

\subsection{Theoretical contributions}

The goal of this study was to expand the current S-D logic exploration of service ecosystem dynamics by adopting an interdisciplinary approach that includes contributions from philosophy and the social sciences. The research question (i.e., How do shared intentions develop from individual agency and contribute to the emergence of service ecosystems?) led us to investigate the process by which interdependent individuals develop shared intentions, thereby driving the emergence of service ecosystems, to gain richer understanding of the levels in that emergence process.

Vargo and Akaka (2012) conceptualize service ecosystems in S-D logic as consisting of relatively static nested levels; conversely, the suggested framework brings out the dynamic nature of service ecosystems by providing a more detailed understanding of the processes by which the macro level emerges from the micro and meso levels (i.e., upward movement and causation) and, in turn, how the macro level provides feedback to and influences the micro and meso levels (i.e., downward movement and causation). The framework breaks down the levels of emergence (Sawyer, 2005) and introduces the dynamics of individual and shared intentionality (Bratman, 2014). As actors move from their own individual intentions to form the we that is essential for service exchange to take place, they engage in interactions. At first, the features that emerge from these interactions are ephemeral, but by facilitating and focusing interactions, they eventually enable more stable features to emerge. As they stabilize, these emergent features become more socially normative and, as such, serve to constrain the ongoing interactions and the agency of participating actors. In other words, a continuous feedback loop occurs at every level between two complementary, causal 
processes: an upward process toward greater interdependence, sociality, and norms (as actors build shared intentions) and a downward process toward greater individual commitment to the shared activity (as interdependence and norms provide a stronger basis for such commitment). As such, this article contributes to the debate surrounding agency and structure by offering a richer understanding of the role of agency (individual and collective) in the step-by-step emergence of service ecosystems.

Each of the five levels plays an important role. Interactions (level B) enable sociality to emerge, and commitment (level A) to this sociality establishes a social structure by mediating the upward and downward processes. The meso level acts as a scaffold: first ephemeral (level C) and then stable (level D) features appear. The first few rungs (though precarious) provide enough assurance to solidify commitment to the continuation of the building process. After the structure is in place, more established access to higher levels beckons, and greater commitment on the part of individuals and groups ensues.

The Sistema B service ecosystem case and the multi-level analysis we present help illustrate the proposed conceptual framework. Each level is brought about as actors' intentions, first individual and then shared, drive them to taking on the actions that allow them to create value while accepting the constraints that come from doing so within a social structure. At the same time, new emerging conditions act to constrain certain possible options or properties.

By dissecting the processes by which this interdependence plays out, we provide greater insights into the resource integration and service exchange processes that take place within a complex ecosystem in which actors are interdependent, often across embedded levels (Akaka et al., 2015). Individual and collective agency and, in particular, intentionality play a crucial role in navigating this complexity: as individuals and groups integrate resources and exchange service, they must adopt courses of action or solutions that create 
value for themselves and others; in turn, these courses of action define and shape the ecosystem. As they receive feedback, actors adjust their course of action, learn and modify practices, and, as a result, continue to shape the whole ecosystem. Complexity turns into choice and opportunities as actors coordinate to fulfill their shared intentions and reach solutions. This process of the emergence of and the sociality flowing from intentionality leads to the development of service ecosystems.

\subsection{Future research directions}

The suggested conceptual framework allows for the exploration of the emergence of service ecosystems as wholes as well as parts. For scholars, this view calls for integrated perspectives that recognize the role of individual and collective agency in relation to structure, and vice versa, in the value co-creation process. This framework opens up several avenues for research from an interdisciplinary perspective.

The links between norms associated with the development of individual and shared intentions and broader institutional arrangements offer an important area of investigation. For example, how do commitment-related norms contribute as "foundational facilitators of value co-creation in markets and elsewhere" (Vargo \& Lusch, 2016, p. 6)? To what extent can commitment-related norms be managed among employees, consumers, and other stakeholders to help foster greater collaboration and ecosystem emergence? Of particular interest would be an analysis of the links between norms and bounded rationality (Bratman, 2014; Simon, 1957; Vargo \& Lusch 2016). For example, what is the role of commitmentrelated norms and other institutions in enabling rationality under conditions of bounded rationality?

Another research direction is the role of individual and collective agency in market formation. How can individual consumers' or employees' problem-solving intentions (Alderson, 1957; Lusch \& Vargo, 2014) be identified and supported to lead to collective 
action and ecosystem emergence and/or market formation? What are the mediators between individual and collective agency in structuring ecosystems? In particular, research could examine the role of communication as a mediator between agency and structure. If representational practices (Kjellberg \& Helgesson, 2006) and emergent communicative features, such as topic, frame, and conversational roles (Sawyer, 2005; Schegloff, 1992), contribute to the emergence of institutions and institutional arrangements, how can managers use such features to support structuration processes? Furthermore, research could try to provide empirical evidence of the emergence process by conducting longitudinal case studies (Siggelkow, 2007) or by formulating propositions linking the development of shared intentionality to ecosystem emergence.

\subsection{Managerial implications}

The emergence of new collaborative market structures such as service ecosystems leads managers to increasingly consider value co-creation. Service ecosystems are not simply an outcome, but rather a strategic perspective that focuses on the complementarity of the service ecosystem as a whole and its individual parts. For managers, this perspective calls for collaborative, integrated action while recognizing the value of individual human agency: from individuals, to single companies, to a network of interrelated resource-integrating value creating systems, and back to the individual.

Knowledge of the nested levels and the role of shared intentionality may help managers in different ways. Level A suggests that managers should consciously seek a clear understanding of their own and their ecosystem partners' intentions and consider how they relate to each other. Level B highlights the importance of seeking opportunities to interact with partners in "quality conversations" to move from the implicit to the explicit and to gain better alignment. Through dialogue, partners can transform the organic development and stabilization of shared knowledge into practices and norms across groups (of consumers or 
employees) in their organization. Managers should also realize that early on these practices and norms create constraints that may limit their freedom to act while guiding behavior and decision making. Level $\mathrm{C}$ shows that only from such a shared understanding can managers establish more strategic and formal procedures, rules, and norms that will develop into a fullfledged infrastructure (level D). Managers can highlight these properties to show evidence of the emergence of a service ecosystem and encourage further collaboration. The move to the next level (level E) requires more formalization; managers can help bring these about by developing strategic plans and partnerships and seeking legal or other types of recognition that will reinforce the foundations of the system.

In short, managers can focus on the development of shared intentions and attempt to make them explicit to actors throughout the organization. By facilitating the development of shared intentionality at each level, they can foster greater value co-creation opportunities. An understanding of the five emergence levels can serve as the basis for a practical analytical and decision-making dashboard to monitor and develop relevant opportunities for resource integration and value co-creation at each level and to enable desirable upward and downward effects. Taking an emergence approach will help managers understand that the development of shared intentionality is a complex, interrelated process of ephemeral and stable emergents, one that is dynamic, open to change, and can be influenced by managerial action.

In conclusion, by highlighting the role of shared intentions and actors' interdependence in service ecosystems, the suggested framework offers novel insights into the emergence of new collaborative market structures. We expand the S-D logic view of service ecosystems by reconciling previously incompatible agency-structure frameworks. By exploring the meso level between the micro (actor) and the macro (ecosystem) levels, we show how individual actors' agency builds into and is reinforced by ecosystem dynamics. This perspective contributes to the management literature on business ecosystem (Iansiti \& 
Levien, 2004; Moore, 1993, 2013; Thomas, 2013; Williamson \& De Meyer, 2012) by underscoring the structuration processes at play in the emergence of ecosystems and by clarifying the role of individual and collective agency and, in particular, intentionality. 


\section{References}

Akaka, M., Vargo, S., \& Schau, H. (2015). The context of experience. Journal of Service Management, 26(2), 206-223.

Alderson, W. (1957). Marketing behavior and executive action. Homewood, IL: Richard D. Irwin.

Archer, M. S. (1982). Morphogenesis versus structuration: On combining structure and action. British Journal of Sociology, 33(4), 455-483.

Archer, M. S. (2000). Being human: The problem of agency. Cambridge: Cambridge University Press.

Bagozzi, R. P. (1974). Marketing as an organized behavioral system of exchange. Journal of Marketing, 38(4), 77-81.

Bagozzi, R. P. (2000). On the concept of intentional social action in consumer behavior. Journal of Consumer Research, 27(3), 388-396.

Bagozzi, R. P., \& Dholakia, U. M. (2002). Intentional social action in virtual communities. Journal of Interactive Marketing, 16(2), 2-21.

Battilana, J., \& D’Aunno, T. (2009). Institutional work and the paradox of embedded agency. In T. B. Lawrence, R. Suddaby, \& B. Leca (Eds.), Institutional work: Actors and agency in institutional studies of organizations (pp. 31-58). New York: Cambridge University Press.

Bhaskar, R. (2008a). A realist theory of science (3rd ed.). London: Verso Press.

Bhaskar, R. (2008b). Dialectic: The pulse off reedom. Oxon: Routledge.

Bourdieu, P. (1977). Outline of a theory ofp ractice. Cambridge: Cambridge University Press.

Bratman, M. E. (1987). Intention, plans, and practical reason. Cambridge, MA: Harvard University Press. 
Bratman, M. (1999). Faces of intention: Selected essays on intention and agency. Cambridge: Cambridge University Press.

Bratman, M. E. (2014). Shared agency: A planning theory of acting together. New York: Oxford University Press.

Buckley, W. (1967). Sociology and modern systems theory. Englewood Cliffs, NJ: Prentice Hall.

Chandler, J., \& Vargo, S. (2011). Contextualization and value-in-context: How context frames exchange. Marketing Theory, 11(10), 35-49.

Chomsky, N. (2002). On nature and language. Cambridge: Cambridge University Press.

Davidson, D. (1999). The emergence of thought. Erkenntnis, 51(1), 511-521.

Gell-Mann, M. (1994). Complex adaptive systems. In G.A. Cowan, D. Pines, \& D. Meltzer (Eds.), Complexity: Metaphors, models, and reality, Santa Fe Institute studies in the sciences of complexity (Vol. XIX, pp. 17-45). Reading, MA: Addison-Wesley.

Giddens, A. (1984). The constitution of society: Outline of the theory of structuration. Chicago: Polity Press.

Gilbert, M. (1990). Walking together: A paradigmatic social phenomenon. Midwest Studies in Philosophy, 15(November), 1-14.

Gummesson, E. (2005). Qualitative research in marketing: Road-map for a wilderness of complexity and unpredictability. European Journal of Marketing, 39(3-4), 309-327.

Gummesson, E., \& Mele, C. (2010). Marketing as value co-creation through network interaction and resource integration. Journal of Business Market Management, 4(4), 181-198. New York: Springer.

Iansiti, M., \& Levien, R. (2004). The keystone advantage. Boston: Harvard Business School Press. 
Kauffman, S. (1995). At home in the universe: The search for laws of self-organization and complexity. New York: Oxford University Press.

Kjellberg, H., \& Helgesson, C. (2006). Multiple versions of markets: Multiplicity and performativity in market practice. Industrial Marketing Management, 35(7), 839-855.

Lusch, R. F., \& Spohrer, J. C. (2012). Evolving service for a complex, resilient, and sustainable world. Journal of Marketing Management, 28(13-14), 1491-1503.

Lusch, R., \& Vargo, S. (2014). Service-dominant logic: Premises, perspectives, possibilities. Cambridge: Cambridge University Press.

MacInnis, D. J. (2011). A framework for conceptual contributions in marketing. Journal of Marketing, 75(4), 136-154.

Maglio, P. P., \& Spohrer, J. (2013). A service science perspective on business model innovation. Industrial Marketing Management, 42(5), 665-670.

Mandelbaum, M. (1951). A note on emergence. In S. W. Baron (Ed.), Freedom and reason: Studies in philosophy and Jewish culture, in memory of Morris Ralph Cohen (pp. 175183). New York: Free Press.

Meehl, P. E., \& Sellars, W. (1956). The concept of emergence. Minnesota studies in the philosophy of science, 1, 239-252.

Mele, C., \& Polese, F. (2011). Key dimensions of service systems in value-creating networks. In H. Demirkan, J. C. Spohrer, \& V. Krishna (Eds.), The science of service systems (pp. 37-59). New York: Springer.

Moore, J. F. (1993). Predators and prey: A new ecology of competition. Harvard Business Review, 71(3), 75-83.

Moore, J. F. (2013). Shared purpose. Seattle: CreateSpace. 
Ng, I. C., Maull, R., \& Yip, N. (2009). Outcome-based contracts as a driver for systems thinking and service-dominant logic in service science: Evidence from the defence industry. European Management Journal, 27(6), 377-387.

Peñaloza, L., \& Mish, J. (2011). The nature and processes of market co-creation in triple bottom line firms: Leveraging insights from consumer culture theory and service dominant logic, Marketing Theory, 11(1), 9-34.

Richardson, L., \& Adams St. Pierre, E. (2000). Writing: A method of Inquiry. In N. Denzin \& Y. Lincoln (Eds.), Handbook of qualitative research (pp. 959-978). London: Sage.

Sawyer, R. K. (2005). Social emergence: Societies as complex systems. Cambridge: Cambridge University Press.

Schegloff, E. A. (1992). In another context. In A. Duranti \& C. Goodwin (Eds.), Rethinking context: Language as an interactive phenomenon. New York: Cambridge University Press.

Searle, J. R. (1983). Intentionality: An essay in the philosophy of mind. Cambridge: Cambridge University Press.

Sewell, W. (1992). A theory of structure: Duality, agency, and transformation. American Journal of Sociology, 98(1), 1-29.

Shapiro, S. J. (2002). Law, plans, and practical reason. Legal Theory, 8, 387-441.

Siggelkow, N. (2007). Persuasion with case studies. Academy of Management Journal, 50, 20-24.

Simon, H. (1957). A behavioral model of rational choice. In H. Simon (Ed.), Models of man, social and rational: Mathematical essays on rational human behavior in a social setting. New York: Wiley.

Spohrer, J., \& Maglio, P. (2010). Towards a science of service systems: Value and symbols. In P. Maglio, C. Kieliszewski, \& J. Spohrer (Eds.), Handbook or service science, 
Service Science: Research and Innovations in the Service economy (pp. 157-194). New York: Springer.

Stanford Encyclopaedia of Philosophy (2015). Agency. Retrieved 10 August, 2015, from http://plato.stanford.edu/entries/agency/.

Stones, R. (2005). Structuration theory. New York: Palgrave Macmillan.

Thomas, L. D. W. (2013). Ecosystem emergence: An investigation of the emergence processes of six digital service ecosystems. Doctoral dissertation, Imperial College London.

Tomasello, M. (2009). Why we cooperate. Cambridge, MA: MIT Press

Van de Ven, A. H., \& Garud, R. (1993). Innovation and industry development: The case of cochlear implants. Research on Technological Innovation, Management and Policy, 5, 1-46.

Vargo, S., \& Akaka, M. (2012). Value co-creation and service systems (re)formation: A service ecosystems view. INFORMS Service Science, 4(3), 207-217.

Vargo, S., \& Lusch, R. (2011). It's all B2B ... and beyond: Toward a systems perspective of the market. Industrial Marketing Management, 40(2), 181-187.

Vargo, S., \& Lusch, R. (2016). Institutions and axioms: An extension and update of servicedominant logic. Journal of the Academy of Marketing Science, 44(1), 5-23.

Williamson, P. J., \& De Meyer, A. (2012). Ecosystem advantage: How to successfully harness the power of partners. California Management Review, 55(1), 24-46. 